\title{
Are Patient-reported Outcome Measures in Orthopaedics Easily Read by Patients?
}

\author{
Ibraheim El-Daly MBBS, MRCS, PgCert, Hajir Ibraheim MBBS, BSc, MRCP, \\ Karthig Rajakulendran MBBS, BSc, MRCS, Paul Culpan MBBS, BSc, MRCS, FRCS (Tr \& Orth), \\ Peter Bates MBBS, BSc, MRCS, FRCS (Tr \& Orth)
}

Received: 16 February 2015/ Accepted: 6 October 2015/Published online: 15 October 2015

(C) The Association of Bone and Joint Surgeons ( 2015

\begin{abstract}
Background Patient-reported outcome measures (PROMs) are commonly used by healthcare providers as means of assessing health-related quality of life and function at any given time. The complexity of PROMs can differ and when combined with varying degrees of adult literacy, error can be introduced if patients fail to understand questions. With an average adult literacy level of 11-year-old students in the United Kingdom, it is unclear to what degree PROMs can be read and understood by most patients (readability); to our knowledge, this has not been evaluated.

Questions/purposes We wished to determine the readability of commonly used PROMs in orthopaedic surgery, as assessed by a validated tool that measures the complexity of the language in these surveys.
\end{abstract}

Each author certifies that he or she, or a member of his or her immediate family, has no funding or commercial associations (eg, consultancies, stock ownership, equity interest, patent/licensing arrangements, etc) that might pose a conflict of interest in connection with the submitted article.

All ICMJE Conflict of Interest Forms for authors and Clinical Orthopaedics and Related Research ${ }^{\circledR}$ editors and board members are on file with the publication and can be viewed on request.

This work was performed at The Royal London Hospital, Barts Health NHS Trust, Department of Trauma and Orthopaedic Surgery, Whitechapel, London, UK

H. Ibraheim, K. Rajakulendran

Department of Trauma and Orthopaedic Surgery, Basildon and

Thurrock University Hospitals, Basildon, Essex, UK

I. El-Daly ( $₫)$, P. Culpan, P. Bates

Department of Trauma and Orthopaedic Surgery, The Royal

London Hospital, Barts Health NHS Trust, Whitechapel,

London, UK

e-mail: Ibraheimel-daly@nhs.net
Methods We performed a MEDLINE search to identify the most-commonly reported PROMs in orthopaedic research. One hundred twenty-one PROMs were identified and reviewed by 19 attending orthopaedic surgeons at our institution. Fifty-nine were selected as the most commonly used in our department. Of these, $52(78 \%)$ were disease specific and included: $12(20 \%)$ knee, $10(17 \%)$ shoulder, seven (12\%) spine, six (10\%) hip, five (8\%) foot and ankle, four $(7 \%)$ elbow, three $(5 \%)$ pelvis, three $(5 \%)$ hand and wrist, and two (3\%) lower limb. The remaining seven (12\%) PROMs were general health questionnaires. The Flesch Reading Ease Score is a validated readability tool measuring average sentence length and syllables per word. It is expressed on a scale from 0 to 100 with higher scores indicating easier reading. We extracted the text from each PROM and inserted it in the same online Flesch Reading Ease Score calculator to generate a score.

Results The mean readability score was 55 (range, 0-93), corresponding to text best understood by 16- to 18-year-old students $\left(11^{\text {th }}-12^{\text {th }}\right.$ grades). Twenty-nine PROMs (49\%) scored less than 60 , classifying them as at least fairly difficult to read. Eight (14\%) scored less than 30, best understood by university graduates. Only seven of 59 PROMs analyzed scored greater than 79 , corresponding to text that can be understood by the average UK adult.

Conclusions The majority of PROMs analyzed are written at a level that is incomprehensible to the average UK adult.

Clinical Relevance This issue needs to be addressed if we are to continue basing our research conclusions on outcome scores. The information obtained is useful for patients to understand their musculoskeletal health, governmental agencies allocating healthcare resources, provision of management guidelines, and as a link to other data sets, such as hospital episodes statistics. Accurate and reliable data can be 
obtained only if patients who complete these evaluations are able to read and understand the questions asked.

\section{Introduction}

\section{Background}

At least seven million adults are functionally illiterate in the United Kingdom (UK), with one in six having a literacy level less than that expected of a 9-year-old [29]; $36 \%$ of Americans ( 89 million) have less than basic health literacy skills [63], and almost $1 / 2$ of all Australians have literacy skills less than the minimum level required to understand and use information from medical texts [6]. These subjects would have difficulty understanding healthcare questionnaires written at a level greater than their reading grade and have poorer health outcomes $[7,11,93]$. Currently an approach to measure healthcare performance is through patient-reported outcome measures (PROMs) [5, 57, 92]. The use of PROMs in the USA is gaining popularity, and is becoming standard practice in the UK, forming an essential part of treatment pathways and determining best practice [19, 51, 81, 94].

\section{Rationale}

Although we know that most online patient education material from the American Academy of Orthopaedic Surgeons is incomprehensible for the average patient, it is unclear whether PROMs are [32]. If we are to continue drawing research conclusions and base future healthcare strategies on PROMs, it is pertinent to identify if patients can comprehend these questionnaires. The Flesch Reading Ease Score (FRES) is a validated technique used to evaluate the ease by which text can be read and understood, defined as readability [2, 37, 53, 70, 99].

\section{Study Purpose}

We therefore sought to determine the readability of commonly used PROMs in orthopaedic surgery, as assessed by a validated readability tool that measures the complexity of the language in these surveys, and matching this to the readers' level of understanding [70].

\section{Materials and Methods}

Many algorithms exist; the most widely used is the FleschKincaid reading grade developed for the US Navy in 1975
$[2,53]$. The FRES is a validated readability tool inversely related to the Flesch-Kincaid grade, which correlates this to the reader's education level. It analyzes the average number of syllables per word and the average number of words in a sentence to calculate a numerical score presented as a number from 0 to 100 (Appendix 1). Higher scores indicate text easily read and understood by individuals from lower school years. Applying this to level of education, a score of 90 to 100 is easily understood by 9-year-old subjects ( $4^{\text {th }}$ grade), 80 to 89 by 11 -year-old subjects ( $6^{\text {th }}$ grade), 70 to 79 by 12 -year-old subjects $\left(7^{\text {th }}\right.$ grade), 60 to 69 by 13 - to 15 -year-old subjects $\left(8^{\text {th }}-10^{\text {th }}\right.$ grades $), 50$ to 59 by 16 - to 18 -year-old subjects $\left(11^{\text {th }}-12^{\text {th }}\right.$ grades), 30 to 49 by 18 - to 22 -year-old subjects (undergraduates), and 0 to 29 by postgraduate students (Table 1) [37].

Among validated readability scores, the FRES was chosen for our study as it is the most commonly used in the assessment of medical material and survey readability [17]. It also is used in numerous other industries such as education and banking, and is the preferred readability score for Microsoft ${ }^{\circledR}$ Office (Microsoft ${ }^{\circledR}$ Corporation, Redmond, WA, USA); US courts accept its use in testimony, and insurance policies are required by federal law to have a FRES of 45 or greater [72, 76, 91]. Applying the FRES to published editorials, the Readers Digest scores greater than 65 , so it is easily understood by 12 -year-old subjects, whereas the Harvard Law Review scores less than 49, so it is best understood by university graduates [46].

To determine which PROMs are commonly used and reported in the orthopaedic literature, a comprehensive MEDLINE search was performed in February 2014 using the keywords: "patient reported" and "scoring system" in combination with "pelvis", "hip", "knee", "ankle", "foot", "hand", "elbow", "shoulder", and "spine".

Abstracts were checked individually by the authors and 121 orthopaedic-specific PROMs were identified. These then were reviewed by 19 attending orthopaedic surgeons from all subspecialties at our institution (Level 1 trauma center) and 59 were selected as most commonly used. Of these, seven $(12 \%)$ were general health questionnaires and the remaining $52(78 \%)$ were disease specific. These included: $12(20 \%)$ knee, $10(17 \%)$ shoulder, seven $(12 \%)$ spine, six (10\%) hip, five $(8 \%)$ foot and ankle, four $(7 \%)$ elbow, three $(5 \%)$ pelvis, three $(5 \%)$ hand and wrist, and two $(3 \%)$ lower limb.

Graphic scales or pictograms were removed from all questionnaires and text was edited to include only words as per guidelines in the readability literature [38]. The extracted text was inserted in the same online FRES calculator after a Google search (www.readability-score.com), generating a score [84]. 
Table 1. Relationship between FRES and minimum level of education required to comprehend text

\begin{tabular}{|c|c|c|c|}
\hline FRES & Readability level & Student age & Education level \\
\hline $90-100$ & Very easy & 9 years old & $4^{\text {th }}$ grade \\
\hline $80-89$ & Easy & 11 years old & $6^{\text {th }}$ grade \\
\hline $70-79$ & Fairly easy & 12 years old & $7^{\text {th }}$ grade \\
\hline $60-69$ & Standard English & 13 to 15 years old & $8^{\text {th }}-10^{\text {th }}$ grades \\
\hline $50-59$ & Fairly difficult & 16 to 18 years old & $11^{\text {th }}-12^{\text {th }}$ grades \\
\hline $30-49$ & Difficult & 18 to 22 years old & Undergraduates \\
\hline $0-29$ & Very difficult & Varies & Postgraduates \\
\hline
\end{tabular}

FRES = Flesch Reading Ease Score.

Table 2. PROMs that can be understood by the average UK adult

\begin{tabular}{ll}
\hline PROMs & $\begin{array}{l}\text { FRES greater } \\
\text { than } 79\end{array}$ \\
\hline Roland-Morris Disability Questionnaire & 93 \\
Oswestry Low Back Pain Score & 83 \\
SF-36 & 83 \\
Lysholm Knee Score & 80 \\
Modified Mayo Wrist Score & 80 \\
Hughston Clinic Knee Self-Assessment & 79 \\
Questionnaire & 79 \\
Copenhagen Neck Disability Scale & \\
\hline
\end{tabular}

PROMs = patient-reported outcome measures; FRES = Flesch Reading Ease Score.

\section{Results}

The mean readability score was 55 (range, 0-93) corresponding to text best understood by 16- to 18-year-old students $\left(11^{\text {th }}-12^{\text {th }}\right.$ grades). Twelve percent (seven of 59) of the PROMs we analyzed scored greater than 79, corresponding to text that can be understood by the average UK adult (Table 2). Of the seven, three were spine (Oswestry Low Back Pain Score, Roland-Morris Disability Questionnaire, Copenhagen Neck Disability Scale), two were knee (Hughston Clinic Knee Self-Assessment Questionnaire, Lysholm Score), one was a general health questionnaire (SF-36), and one was a hand and wrist PROM (Modified Mayo Wrist Score). Knee PROMs had the widest FRES range (range, 0-80); of those, two of 12 scored greater than 79 (Lysholm and Hughston Clinic scores), whereas four of 12 scored less than 29, corresponding to text best understood by postgraduates (Knee Outcome Survey, Cincinnati Knee Rating System, IKDC, Tegner Activity Scale). Two of three pelvic PROMs analyzed scored 0 (Iowa and Majeed pelvic scores) (Table 3). The Roland-Morris Disability Questionnaire had the highest readability score (FRES 93), while the University of California-Los Angeles (UCLA) Activity Scale, Knee
Outcome Survey, Iowa Pelvic Score, and Majeed Pelvic Score had the lowest (FRES 0) (Table 4).

\section{Discussion}

We found that a surprising number of PROMs were likely to be unreadable and potentially incomprehensible to most patients asked to complete them. As information from PROMs are helpful to patients in understanding their musculoskeletal health and to those assessing the health care patients receive $[20,31,43]$, it is important that these data are accurate and reliable. Our study highlights the importance of readability, which may be overlooked in the design of commonly used orthopaedic PROMs, at least as assessed by the FRES.

This study had several potential limitations. Our study focused only on the readability of text determined through use of mathematical algorithms matching text to the readers understanding producing a score. We did not assess the readability of document design, such as use of color, font size or type, difficulty of concepts conferred, and level of readers' interest toward the text [45]. PROMs using visual aids such as a series of boxes going from "I totally disagree" to "I totally agree" or a sliding bar from "good" to "bad" may affect the readability of our results. We also did not consider the reader's familiarity with a subject, for example, patients who have long-term diabetes may be more familiar with disease-related terminology compared with patients with newly diagnosed diabetes. Furthermore our study tested only the readability of the entire document, as opposed to analyzing each question. This does not reflect variation in the readability of individual items. We did not assess whether this would apply to other language translations of these PROMs. FRES considers long polysyllabic words less readable. This may not be true for all terms; for example, "disability" has five syllables producing a low score but otherwise is easily understood. Other validated readability formulas use different mathematical algorithms 
Table 3. PROMs by region with corresponding Flesch Reading Ease Score

\begin{tabular}{ll}
\hline PROMs & FRES \\
\hline Hip &
\end{tabular}

WOMAC hip score [59]

Hip disability and Osteoarthritis Outcome Score [59] 35

Lequesne Index of Severity for Osteoarthritis of the Hip [65] 35

Oxford Hip Score [27]

Copenhagen Hip and Groin Outcome Score [98]

Hip disability and Osteoarthritis Outcome Score-Physical 64

Function Short Form [22]

Knee

Knee Outcome Survey [69]

IKDC [44]

Tegner Activity Scale [96]

Cincinnati Knee Rating System [1]

Knee injury and Osteoarthritis Outcome Score [89]

WOMAC knee score [90]

Kujala [62]

Oxford Knee Score [28]

Anterior Cruciate Ligament Quality Of Life [73]

Western Ontario Meniscal Evaluation Tool [57]

Hughston Clinic Knee Self-Assessment Questionnaire [36] 79

Lysholm Knee Score [66]

UCLA Activity Scale [111]

Lower limb

Lower Extremity Functional Scale [12]

Elbow

The American Shoulder and Elbow Surgeons-

Elbow score [54]

Mayo Elbow Performance Score [74]

Oxford Elbow Score [24]

Kerlan-Jobe Orthopaedic Clinic Shoulder and Elbow score [8]

DASH [47]

Quick-DASH [9]

Shoulder

Oxford Shoulder Score [25]

Oxford Instability Score [25, 26]

American Shoulder and Elbow Surgeons [54]

Western Ontario Osteoarthritis of the Shoulder [61]

Western Ontario Rotator Cuff Index [55]

Western Ontario Shoulder Instability Index [56]

Shoulder Pain and Disability Index [85]

Simple Shoulder Test [86]

Wrist and hand

Michigan Hand Outcome Questionnaire [19]

Patient-Rated Wrist/Hand Evaluation [67]

Modified Mayo Wrist Score [4]

Spine

Quebec Back Pain Disability Scale [60]
Table 3. continued

\begin{tabular}{lc}
\hline PROMs & FRES \\
\hline Oswestry Low Back Pain Score [35] & 83 \\
Roland-Morris Disability Questionnaire [87] & 93 \\
The Neck Disability Index [101] & 62 \\
Copenhagen Neck Disability Scale [49] & 79 \\
The Bournemouth Back Questionnaire [13] & 76 \\
The Bournemouth Neck Questionnaire [14] & 74 \\
Foot and ankle & \\
Kaikkonen Functional Scale [50] & 59 \\
Foot and Ankle Outcome Score [88] & 70 \\
Foot and Ankle Disability Index [42] & 72 \\
AAOS Foot and Ankle Questionnaire [48] & 73 \\
Foot Function Index [15] & 74 \\
Pelvis & \\
Iowa Pelvic Score [97] & 0 \\
Majeed Pelvic Score [68] & 0 \\
Short Musculoskeletal Function Assessment [95] & 63 \\
SF-12 [107] & 78 \\
Health questionnaire & \\
Stanford Health Assessment Questionnaire [82] & 78 \\
SF-36 [108] & 83 \\
Physical Activity Scale For The Elderly [109] & 65 \\
Euroqol-5D [34] & 53 \\
Pain questionnaire & \\
McGill Pain Questionnaire [71] & 64 \\
Dallas Pain Questionnaire [64] & \\
\hline
\end{tabular}

PROM = patient-reported outcome measure; FRES = Flesch Reading Ease Score; AAOS = American Academy of Orthopaedic Surgeons.

to measure semantic (words and sentences) and syntactic elements (syllables and sentences) to determine the readability of text [70]. Applying different formulas to the same text may yield different results, whereas selecting a single formula could bias our results. For example, applying the Simplified Measure of Gobbledygook (SMOG) formula to the DASH questionnaire gives a score that indicates it would be easily understood by 12 -year-old subjects $\left(7^{\text {th }}\right.$ grade), whereas using the FRES formula suggests it is best understood by 18- to 22-year-old subjects (undergraduates) $[2,46]$. Because we did not compare the FRES with other readability scores, our results can apply only to FRES. Although we assessed the readability of commonly used PROMs at our institution, our selection process is open to selection bias and therefore numerous PROMs used by orthopaedic surgeons elsewhere may not have been included. In addition we made no attempt to rank PROMs in terms of how frequently they appear in the literature.

Non-English PROMs were not assessed as most readability scores are not validated for use in any other 
Table 4. PROMs categorized by minimum level of education required to understand questionnaire based on FRES score

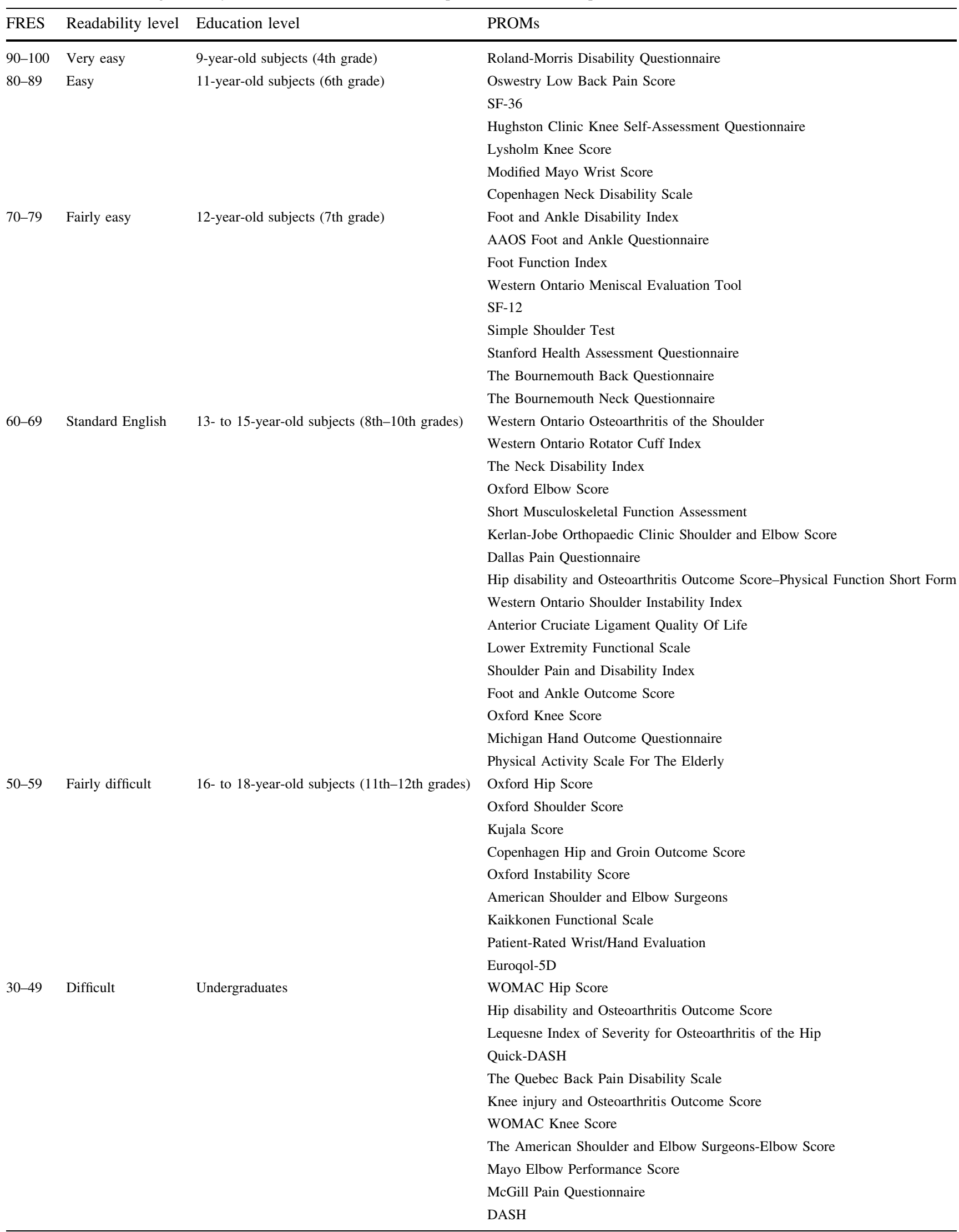


Table 4. continued

\begin{tabular}{llll}
\hline FRES & Readability level & Education level & PROMs \\
\hline $0-29$ & Very difficult & Postgraduates & Knee Outcome Survey \\
& & & University of California, Los Angeles Activity Scale \\
& & Iowa Pelvic Score \\
& & Majeed Pelvic Score \\
& & IKDC \\
& Tegner Activity Scale \\
& Cincinnati Knee Rating System \\
\hline
\end{tabular}

PROMs = patient-reported outcome measures; FRES = Flesch Reading Ease Score; AAOS = American Academy of Orthopaedic Surgeons.

language. Despite these limitations, readability formulas are useful in providing a benchmark for comparison when revising text. A better perspective might have been achieved through an average readability score derived from several formulas, although this method has not been validated in the readability literature.

With the majority of medical negligence claims related to poor communication, it is essential that written healthcare material be easily understood [10]. In 1999 Tampa General Hospital paid USD 3.8 million in compensation because signed consent forms were written at a level that exceeded patients' understanding [46, 99]. Medical organizations in the European Union are legally liable for text that is difficult to understand [16]. In the US, the Plain Writing Act of 2010 was introduced legislating that written healthcare information be understood by adults with average literacy skills [83].

Our results are consistent with those of previous studies that most healthcare information is written at a level greater than patient understanding [23, 33, 39, 41, 102, 104, 105]. However, there is no evidence to suggest that lower literacy levels affect the quality of PROMs data collected.

Only $12 \%$ of the PROMs analyzed could be read and understood by the average UK adult; $1 / 2$ of these $12 \%$ were spine PROMS. Thirty-one percent are best understood by university graduates. None of the shoulder, elbow, pelvis, hip, foot, or ankle PROMs met the national average readability requirements. Two of three pelvic PROMs scored zero suggesting the highest literacy level required to complete these questionnaires. UK national standard PROMs (Oxford hip and knee scores) exceeded the average readability requirements [29], at best understood by adults with a literacy level of 13- to 15-year-old subjects (Oxford Knee Score $=$ FRES 59), at worst by college graduates (Oxford Hip Score = FRES 54). Similarly, the preferred outcome measure for use by the Department of Health (EuroQol-5D) is best understood by patients with literacy levels of 17- to 18-year-old subjects (12 ${ }^{\text {th }}$ grade) (FRES 53) $[5,30]$.

Stigma surrounding adults struggling to read often leaves them uncomfortable disclosing any literacy difficulties [80]. Because patients with low literacy skills ask fewer questions concerning information they do not understand, PROMs may be completed incorrectly, leading to unreliable data [52]. However, difficulties associated with comprehension are not exclusive to patients with low literacy. Patients with proficient literacy skills may not seek clarification to avoid embarrassment or appearing ignorant [110]. Equally it cannot be assumed that patients with difficulties understanding fail to seek clarification. For this reason clinicians should identify patients who may struggle, using validated screening tools (Appendix 2) [18, 75, 78, 103]. Despite this clinicians may fail to identify patients with low health literacy and should consider producing "health-literate" PROMs written at or below the level of an 11-year-old subject [21, 40, 106].

To achieve this, writers should determine which medical words are important for patients understanding and where possible, substitute with "plain language" alternatives, for example, swelling rather than edema, and break rather than fracture. Alternatives that change the meaning but improve the readability score should be avoided. Each medical word used should be carefully selected and where appropriate offer an easy to understand explanation or definition for patient reference. Applying these basic principles (Table 5) can facilitate patient-friendly questionnaires by concentrating on ensuring the general content, complexity, and format are easy to understand [100, 110].

Although shortening sentences may decrease the readability score, it can make it more difficult to understand. Simplifying text using common words that are monosyllabic and bisyllabic, creating shorter more-simple sentences will improve readability while avoiding this limitation. For example, if we take an item from the UCLA Activity Scale that reads: "Wholly inactive, dependent on 
Table 5. Guidelines for writing easy-to-read health-related material

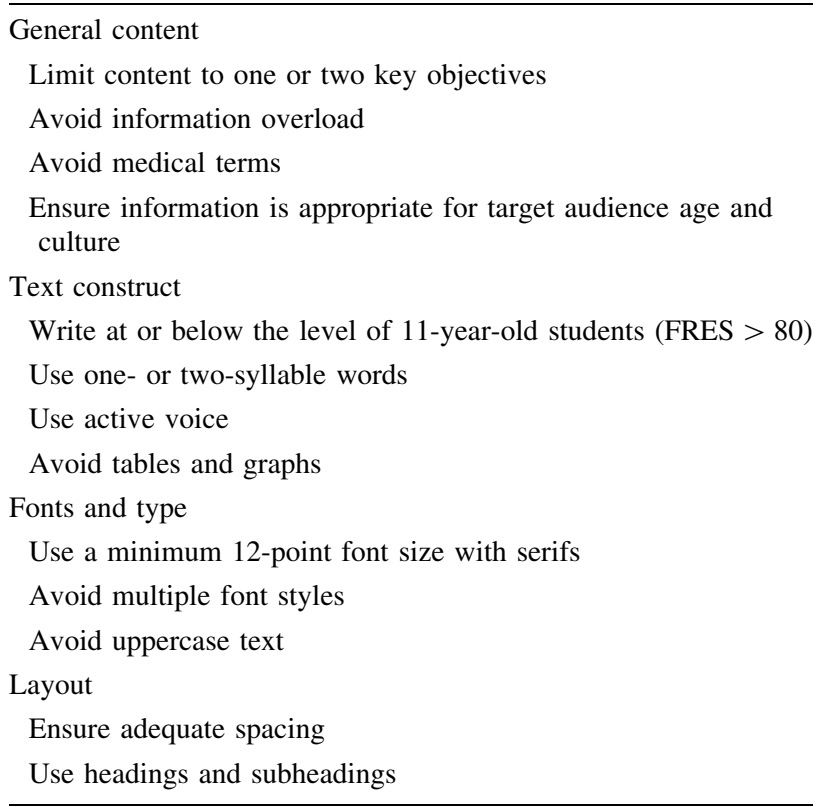

FRES = Flesch Reading Ease Score.

others, and cannot leave residence", gives a FRES of 44, which corresponds to text that is difficult to read and is best understood by undergraduates. This can be rewritten to read: "In need of help from others and unable to leave the house", producing a FRES of 89, corresponding to text that is easily read and understood by 11-year-old subjects (average adult).

Any method used to improve the readability of PROMs will require additional resources to validate this. To establish whether to invest in such resources, further studies are needed to determine whether PROMs with a low readability score would yield substantially different answers if they were rewritten with a higher readability score.

To ensure subsequent interventions are effective and avoid unreliable data, it is crucial that clinicians consider varying levels of health literacy when collecting PROMs data $[3,58,77,79]$. This can be facilitated by ensuring PROMs are written at or below the average literacy level of the population they are meant to survey [1].

\section{Appendix 1: The FRES Algorithm}

The FRES algorithm used to produce a readability score analyzes the average number of syllables per word and the average number of words in a sentence to calculate a numerical score presented as a number from 0 to 100 .

FRES $=206.835:(84.6 s-1.015 \mathrm{w})$ $\mathrm{s}=$ the average number of syllables per word; $\mathrm{w}=$ the average number of words per sentence.

\section{Appendix 2: The Single Question Screen}

The single question screen is a validated tool that can be used to identify patients with low health literacy who may struggle to read and understand PROMs.

"How often do you need someone to help you read instructions, leaflets, or other written material from your doctor or pharmacist?"

- Positive answers: "sometimes," "often," or "always"

"How confident are you in filling out medical questionnaires by yourself?"

- Positive answers: "somewhat," "a little bit," or "not at all”

\section{References}

1. Agel J, LaPrade RF. Assessment of differences between the modified Cincinnati and International Knee Documentation Committee patient outcome scores: a prospective study. Am J Sports Med. 2009;2151-2157.

2. Albright J, de Guzman C, Acebo, P, Paiva D, Faulkner M, Swanson J. Readability of patient education materials: implications for clinical practice. Appl Nurs Res. 1996;9:139-143.

3. Alvey J, Palmer S, Otter S. A comparison of the readability of two patient-reported outcome measures used to evaluate foot surgery. J Foot Ankle Surg. 2012;51:412-414.

4. Amadio PC, Berquist TH, Smith DK, Ilstrup DM, Cooney WP 3rd, Linscheid RL. Scaphoid malunion. J Hand Surg Am. 1989;14:679-687.

5. American Medical Association. Outcomes Research Resource Guide 1997: A Survey of Current Activities. Chicago, IL: American Medical Association; 1997.

6. Australian Bureau of Statistics. 4228.0 - Adult Literacy and Life Skills Survey, Summary Results, Australia, 2006 (Reissue). Available at: http://www.abs.gov.au/AUSSTATS/abs@.nsf/ Lookup/4228.0Main+Features12006\%20(Reissue). Accessed August 19, 2015.

7. Baker DW, Wolf MS, Feinglass J, Thompson JA, Gazmararian JA, Huang J. Health literacy and mortality among elderly persons. Arch Intern Med. 2007;167:1503-1509.

8. Beaton DE, Katz JN, Fossel AH, Wright JG, Tarasuk V. Measuring the whole or the parts? Validity, reliability, and responsiveness of the disabilities of the arm, shoulder and hand outcome measure in different regions of the upper extremity. $J$ Hand Ther. 2001;14:128-146.

9. Beaton DE, Wright JG, Katz JN. Development of the QuickDASH: comparison of three item-reduction approaches. J Bone Joint Surg Am. 2005;87:1038-1046.

10. Beckman HB, Markakis KM, Suchman AL, Frankel RM. The doctor-patient relationship and malpractice: lessons from plaintiff depositions. Arch Intern Med. 1994;154:1365-1370.

11. Berkman ND, Sheridan SL, Donahue KE, Halpern DJ, Crotty K. Low health literacy and health outcomes: an updated systematic review. Ann Intern Med. 2011;155:97-107. 
12. Binkley JM, Stratford PW, Lott SA, Riddle DL. The Lower Extremity Functional Scale (LEFS): scale development, measurement properties, and clinical application. North American Orthopaedic Rehabilitation Research Network. Phys Ther. 1999;79:371-383.

13. Bolton JE, Breen AC. The Bournemouth Questionnaire: a shortform comprehensive outcome measure: I. Psychometric properties in back pain patients. J Manipulative Physiol Ther. 1999;22:503-510.

14. Bolton JE, Humphreys BK. The Bournemouth Questionnaire: a short-form comprehensive outcome measure: II. Psychometric properties in neck pain patients. J Manipulative Physiol Ther. 2002;25:141-148.

15. Budiman-Mak E, Conrad KJ, Roach KE. The Foot Function Index: a measure of foot pain and disability. J Clin Epidemiol. 1991;44:561-570.

16. Burton S. A worldwide phenomenon. Intercom. 2007;54:3. Available at: http://intercom.stc.org/. Accessed September 01, 2015.

17. Calderón JL, Morales LS, Liu H, Hays RD. Variation in the readability of items within surveys. Am J Med Qual. 2006; 21:49-56.

18. Chew LD, Bradley KA, Boyko EJ. Brief questions to identify patients with inadequate health literacy. Fam Med. 2004;36: 588-594.

19. Chung KC, Pillsbury MS, Walters MR, Hayward RA. Reliability and validity testing of the Michigan Hand Outcomes Questionnaire. J Hand Surg Am. 1998;575-587.

20. Clancy C, Collins FS. Patient-Centered Outcomes Research Institute: the intersection of science and health care. Sci Transl Med. 2010;2:37cm18.

21. Cotugna N, Vickery CE, Carpenter-Haefele KM. Evaluation of literacy level of patient education pages in health-related journals. J Commun Health. 2005;30:213-219.

22. Davis AM, Perruccio AV, Canizares M, Tennant A, Hawker GA, Conaghan PG, Roos EM, Jordan JM, Maillefert JF, Dougados M, Lohmander LS. The development of a short measure of physical function for hip OA HOOS-Physical Function Shortform (HOOS-PS): an OARSI/OMERACT initiative. Osteoarthritis Cartilage. 2008;16:551-559.

23. Davis TC, Mayeaux EJ, Frederickson D, Bocchini JA Jr, Jackson RH, Murphy PW. Reading ability of parents compared with reading level of pediatric patient education materials. Pediatrics. 1994;93:460-468.

24. Dawson J, Doll H, Boller I, Fitzpatrick R, Little C, Rees J, Jenkinson C, Carr AJ. The development and validation of a patient-reported questionnaire to assess outcomes of elbow surgery. J Bone Joint Surg Br. 2008;90:466-473.

25. Dawson J, Fitzpatrick R, Carr A. Questionnaire on the perceptions of patients about shoulder surgery. J Bone Joint Surg Br. 1996;78:593-600.

26. Dawson J, Fitzpatrick R, Carr A. The assessment of shoulder instability. J Bone Joint Surg Br. 1999;81:420-426.

27. Dawson J, Fitzpatrick R, Carr A, Murray D. Questionnaire on the perceptions of patients about total hip replacement. $J$ Bone Joint Surg Br. 1996;78:185-190.

28. Dawson J, Fitzpatrick R, Murray D, Carr A. Questionnaire on the perceptions of patients about total knee replacement. J Bone Joint Surg Br. 1998;80:63-69.

29. Department for Business Innovation \& Skills, Gov.UK. Research and Analysis: 2011Skills For Life Survey. Available at: https://www.gov.uk/government/publications/2011-skillsfor-life-survey. Accessed October 18, 2013.

30. Department of Health. Patient Reported Outcome Measures (PROMs) in England: A Methodology for Identifying Potential Outliers. Available at: https://www.gov.uk/government/uploads/ system/uploads/attachment_data/file/216651/dh_128447.pdf. Accessed November 2, 2013.

31. Devlin N, Appleby J. Getting the Most Out of PROMs: Putting Health Outcomes at the Heart of NHS Decision-Making. London, UK: The King's Fund; 2010. Available at: https://www. kingsfund.org.uk/sites/files/kf/Getting-the-most-out-of-PROMsNancy-Devlin-John-Appleby-Kings-Fund-March-2010.pdf. Accessed October 6, 2015.

32. Eltorai AE, Sharma P, Wang J, Daniels AH. Most American Academy of Orthopaedic Surgeons' online patient education material exceeds average patient reading level. Clin Orthop Relat Res. 2015;473:1181-1186.

33. Estrada CA, Hryniewicz MM, Higgs VB, Collins C, Byrd JC. Anticoagulant patient information material is written at high readability levels. Stroke. 2000;31:2966-2970.

34. EuroQol Group. EuroQol: a new facility for the measurement of health-related quality-of-life. Health Policy. 1990;16:199-208.

35. Fairbank JC, Couper J, Davies JB, O'Brien JP. The Oswestry low back pain disability questionnaire. Physiotherapy. 1980;66: 271-273.

36. Flandry F, Hunt JP, Terry GC, Hughston JC. Analysis of subjective knee complaints using visual analog scales. Am J Sports Med. 1991;19:112-118.

37. Flesch R. A new readability yardstick. J Appl Psychol. 1948;32:221-233.

38. Friedman DB, Hoffman-Goetz L. A systematic review of readability and comprehension instruments used for print and webbased cancer information. Health Educ Behav. 2006;33:352373.

39. Glazer HR, Kirk LM, Bosler FE. Patient education pamphlets about prevention, detection, and treatment of breast cancer for low literacy women. Patient Educ Couns. 1996;27:185-189.

40. Goldstein AA, Sikali E, White SR. National assessment of adult literacy (NAAL). Washington, DC: National Center for Education Statistics; 2003. Available at: https://nces.ed.gov/ pubs2007/2007064.pdf. Accessed October 2, 2015.

41. Griffin J, McKenna K, Tooth L. Discrepancy between older clients' ability to read and comprehend and the reading level of written educational materials used by occupational therapists. Am J Occup Ther. 2006;60:70-80.

42. Hale S, Hertel J. Reliability and sensitivity of the Foot and Ankle Disability Index in subjects with chronic ankle instability. J Athl Train. 2005;40:35-40.

43. Health \& Social Care Information Centre. Hospital Episode Statistics. Available at: http://www.hscic.gov.uk/hes. Accessed December 10, 2013.

44. Higgins LD, Taylor MK, Park D, Ghodadra N, Marchant M, Pietrobon R, Cook C; International Knee Documentation Committee. Reliability and validity of the International Knee Documentation Committee (IKDC) Subjective Knee Form. Joint Bone Spine. 2007;74:594-599.

45. Hochhauser M. Some overlooked aspects of consent form readability. IRB. 1997;19:5-9.

46. Hochhauser M. The informed consent form: document development and evaluation. Drug Information Journal. 2000;34: 1309-1317.

47. Jester A, Harth A, Germann G. Measuring levels of upper-extremity disability in employed adults using the DASH Questionnaire. J Hand Surg Am. 2005;30:1074.e1-1074.e10.

48. Johanson NA, Liang MH, Daltroy L, Rudicel S, Richmond J. American Academy of Orthopaedic Surgeons lower limb outcomes assessment instruments: reliability, validity, and sensitivity to change. J Bone Joint Surg Am. 2004;86:902-909.

49. Jordan A, Manniche C, Mosdal C, Hindsberger C. The Copenhagen Neck Functional Disability Scale: a study of reliability and validity. J Manipulative Physiol Ther. 1998;21:520-527. 
50. Kaikkonen A, Kannus P, Jarvinen M. A performance test protocol and scoring scale for the evaluation of ankle injuries. Am J Sports Med. 1994;22:462-469.

51. Kane RL. Introduction. Understanding Health Care Outcomes Research. $2^{\text {nd }}$ ed. Sudbury, MA: Jones and Bartlett Publishers; 2006:3-22.

52. Katz MG, Jacobson TA, Veledar E, Kripalani S. Patient literacy and question-asking behavior in the medical encounter: a mixedmethods analysis. J Gen Intern Med. 2007;22:782-786.

53. Kincaid JP, Fishburne RP Jr, Rogers RL, Chissom BS. Derivation of New Readability Formulas (Automated Readability Index, Fog Count, and Flesch Reading Ease Formula) for Navy Enlisted Personnel. Report no: 8-75, 1975. Available at: http://www.google.co.uk/url? sa=t\&rct=j\&q=\&esrc=s\&source $=$ web\&cd $=1 \&$ ved $=0 \mathrm{CCMQFjAA \& url}=\mathrm{http} \% 3 \mathrm{~A} \% 2 \mathrm{~F} \% 2 \mathrm{Fwww}$. dtic.mil $\% 2$ Fdtic $\% 2$ Ftr $\% 2$ Ffulltext $\% 2 \mathrm{Fu} 2 \% 2 \mathrm{Fa} 006655$.pdf\&ei= bOZuVdvdK4OssgH85IP4Bw\&usg=AFQjCNGKH51CQphw Obz77Cev6nTBm3ANPw\&sig2=UMunFM75bl1D0qGok3vV-g. Accessed August 20, 2015.

54. King GJ, Richards RR, Zuckerman JD, Blasier R, Dillman C, Friedman RJ, Gartsman GM, Iannotti JP, Murnahan JP, Mow VC, Woo SL. A standardized method for assessment of elbow function: Research Committee, American Shoulder and Elbow Surgeons. J Shoulder Elbow Surg. 1999;8:351-354.

55. Kirkley A, Griffin S, Alvarez C. The development and evaluation of a disease-specific quality of life measurement tool for rotator cuff disease: The Western Ontario Rotator Cuff Index (WORC). Clin J Sport Med. 2003;13:84-92.

56. Kirkley A, Griffin S, McLintock H, Ng L. The development and evaluation of a disease-specific quality of life measurement tool for shoulder instability: The Western Ontario Shoulder instability Index (WOSI). Am J Sports Med. 1998;26:764-772.

57. Kirkley A, Griffin S, Whelan D. The development and validation of a quality of life-measurement tool for patients with meniscal pathology: the Western Ontario Meniscal Evaluation Tool (WOMET). Clin J Sport Med. 2007;17:349-356.

58. Kirshner B, Guyatt G. A methodological framework for assessing health indices. J Chron Dis. 1985;38:27-36.

59. Klassbo M, Larsson E, Mannevik E. Hip disability and osteoarthritis outcome score: an extension of the Western Ontario and McMaster Universities Osteoarthritis Index. Scand J Rheumatol. 2003;32:46-51.

60. Kopec JA, Esdaile JM, Abrahamowicz M, Abenhaim L, WoodDauphinee S, Lamping DL, Williams JI. The Quebec Back Pain Disability Scale: measurement properties. Spine (Phila $\mathrm{Pa}$ 1976). 1995;20:341-352.

61. Kuhn JE. The assessment of outcomes for the treatment of the overhead athlete. In: Krishnan SG, Hawkins RJ, Warren RF, eds. The Shoulder and the Overhead Athlete. Philadelphia, PA: Lippincott-Williams \& Wilkins; 2004;33-48.

62. Kujala UM, Jaakkola LH, Koskinen SK, Taimela S, Hurme M, Nelimarkka O. Scoring of patellofemoral disorders. Arthroscopy. 1993;9:159-163.

63. Kutner M, Greenberg E, Jin Y, Paulsen C. The Health Literacy of America's Adults: Results From the 2003 National Assessment of Adult Literacy. Washington DC: U.S. Department of Education, National Center for Education Statistics. 2006. Available at: https://nces.ed.gov/pubsearch/pubsinfo.asp?pubid= 2006483. Accessed August 20, 2015.

64. Lawlis GF, Cuencas R, Selby D, McCoy CE. The development of Dallas pain questionnaire: an assessment of the impact of spinal pain on behavior. Spine (Phila Pa 1976). 1989;14:515-516.

65. Lequesne MG, Mery C, Samson M, Gerard P. Indexes of severity for osteoarthritis of the hip and knee: validation: value in comparison with other assessment tests. Scand J Rheumatol Suppl. 1987;65:85-89.
66. Lysholm J, Gillquist J. Evaluation of knee ligament surgery results with special emphasis on use of a scoring scale. Am J Sports Med. 1982;10:150-154.

67. MacDermid JC. Development of a scale for patient rating of wrist pain and disability. J Hand Ther. 1996;9:178-183.

68. Majeed SA. Grading the outcome of pelvic fractures. $J$ Bone Joint Surg Br. 1989;71: 304-306.

69. Marx G. Patient-reported measure of knee function. J Bone Joint Surg Am. 2000;82:1199-1202.

70. McLaughlin GH. SMOG grading: a new readability formula. J Reading. 1969;12:639-646.

71. Melzack R. The McGill Pain Questionnaire: major properties and scoring methods. Pain. 1975;1:277-299.

72. Microsoft ${ }^{\mathbb{R}}$ Corporation, Office Support. Test your document's readability. Available at: https://support.office.com/en-us/ article/Test-your-document-s-readability-0adc0e9a-b3fb-4bde85f4-c9e88926c6aa. Accessed August 20, 2015.

73. Mohtadi N. Development and validation of the quality of life outcome measure (questionnaire) for chronic anterior cruciate ligament deficiency. Am J Sports Med. 1998;26:350-359.

74. Morrey BF, Sanchez-Sotelo J, eds. The Elbow and its Disorders. 2nd ed. Philadelphia, PA: WB Saunders; 1993.

75. Morris NS, MacLean CD, Chew LD, Littenberg B. The Single Item Literacy Screener: evaluation of a brief instrument to identify limited reading ability. BMC Fam Prac. 2006;7:21.

76. MyFloridaHouse.gov. Flsenate.gov Archives. The Florida Senate. 2011 Florida Statutes. Title XXXVII. Chapter 627. Section 4145 (1a). Available at: http://www.flsenate.gov/laws/ statutes/2011/627.4145. Accessed September 18, 2013.

77. National Academy on an Aging Society. Fact sheet: Low health literacy skills increase annual health care expenditures by $\$ 73$ billion. Available at: $\mathrm{http} / / / \mathrm{www}$.agingsociety.org/agingsociety/publications/ fact/fact_low.htmlhttp://www.agingsociety.org/agingsociety/pub lications/fact/fact_low.html. Accessed August 20, 2013.

78. National Literacy Trust. How can I assess the readability of my document or write more clearly? Available at: http://www. literacytrust.org.uk/about/faqs/710_how_can_i_assess_the_read ability_of_my_document_or_write_more_clearly. Accessed August 20, 2015.

79. Nielsen-Bohlman L, Panzer AM, Kindig DA; Committee on Health Literacy. What is health literacy. Health Literacy: A Prescription to End Confusion. Washington, DC: National Academies Press; 2004:31-58.

80. Parikh NS, Parker RM, Nurss JR, Baker DW, Williams MV. Shame and health literacy: the unspoken connection. Patient Educ Couns. 1996;27:33-39.

81. Patsopoulos NA, Analatos AA, Ioannidis JP. Relative citation impact of various study designs in the health sciences. JAMA. 2005;293:2362-2366.

82. Pincus T, Summey JA, Soraci SA Jr, Wallston KA, Hummon NP. Assessment of patient satisfaction in activities of daily living using a modified Stanford Health Assessment Questionnaire. Arthritis Rheum. 1983;26:1346-53.

83. Plain Language.gov. Federal Plain Language Guidelines. Available at: http://www.plainlanguage.gov/howto/guidelines/ FederalPLGuidelines/index.cfm?CFID $=3423844 \&$ CFTOKEN $=$ d992d224a813db35-C72A3F3D-0E69-0D80-F3B25F21585EC5 43\&jsessionid=E59A53B53D843284822F9F35F5D165E7.chh. Accessed August 11, 2013.

84. Readability score. Available at: https://readability-score.com/. Accessed October 6, 2015.

85. Roach KE, Budiman-Mak E, Sangsiridej N, Lertrantanakul Y. Development of a shoulder pain and disability index. Arthritis Care Res. 1991;4:143-149.

86. Roddey TS, Olson SL, Cook KF, Gartsman GM, Hanten W. Comparisons of the University of California-Los Angeles 
Shoulder Scale and the Simple Shoulder Test with the shoulder pain and disability index: single-administration reliability and validity. Phys Ther. 2000;80:759-768.

87. Roland M, Morris R. A study of the natural history of back pain. Part I: development of a reliable and sensitive measure of disability in low-back pain. Spine (Phila Pa 1976). 1983;8:141144.

88. Roos EM, Brandsson S, Karlsson J. Validation of the foot and ankle outcome score for ankle ligament reconstruction. Foot Ankle Int. 2001;22:788-794.

89. Roos EM, Roos HP, Lohmander LS, Ekdahl C, Beynnon BD. Knee Injury and Osteoarthritis Outcome Score (KOOS): development of a self-administered outcome measure. J Orthop Sports Phys Ther. 1998;28:88-96.

90. Roos EM, Toksvig-Larsen S. Knee injury and Osteoarthritis Outcome Score (KOOS): validation and comparison to the WOMAC in total knee replacement. Health Qual Life Outcomes. 2003;1:17.

91. Stockmeyer NO. Using Microsoft Word's readability program. Michigan Bar J. 2009;88:46-47.

92. Streiner DL, Norman GR, eds. Health Measurement Scales: A Practical Guide to Their Development and Use. New York, NY: Oxford University Press; 1995.

93. Sudore RL, Yaffe K, Satterfield S, Harris TB, Mehta KM, Simonsick EM, Newman AB, Rosano C, Rooks R, Rubin SM, Ayonayon HN, Schillinger D. Limited literacy and mortality in the elderly: the health, aging, and body composition study. J Gen Intern Med. 2006;21:806-812.

94. Suk M, Hanson BP, Norvell DC, Helfet DL. Musculoskeletal Outcomes Measures and Instruments. New York, NY: Thieme Medical Publishers; 2005.

95. Swiontkowski MF, Engelberg R, Martin DP, Agel J. Short musculoskeletal function assessment questionnaire: validity, reliability, and responsiveness. $J$ Bone Joint Surg Am. 1999;81:1245-1260.

96. Tegner Y, Lysholm J. Rating systems in the evaluation of knee ligament injuries. Clin Orthop Relat Res. 1985;198:43-49.

97. Templeman D, Goulet J, Duwelius PJ, Olson S, Davidson M. Internal fixation of displaced fractures of the sacrum. Clin Orthop Relat Res. 1996;329:180-185.

98. Thorborg K, Hölmich P, Christensen R, Petersen J, Roos EM. The Copenhagen Hip and Groin Outcome Score (HAGOS): development and validation according to the COSMIN checklist. Br J Sports Med. 2011;45:478-491.

99. Tinker MA. Introduction. Legibility of Print. Ames, IA: Iowa State University Press; 1963:1-8.

100. U.S. National Library of Medicine. How to write easy-to-read health materials. Available at: https://www.nlm.nih.gov/ medlineplus/etr.html. Accessed November 2, 2013.

101. Vernon H, Mior S. The Neck Disability Index: a study of reliability and validity. J Manipulative Physiol Ther. 1991;14:409415.

102. Wallace LS, Rogers E, Turner L, Keenum A, Weiss BD. Suitability of written supplemental materials available on the Internet for non-prescription medications. Am J Health System Pharm. 2006;63:71-78.

103. Wallace LS, Rogers ES, Roskos SE, Holiday DB, Weiss BD. Brief report: screening items to identify patients with limited health literacy skills. J Gen Intern Med. 2006;21:874-877.

104. Wallace LS, Roskos SE, Weiss BD. Readability characteristics of consumer medication information for asthma inhalation devices. J Asthma. 2006;43:375-378.

105. Wallace LS, Turner LW, Ballard JE, Keenum AJ, Weiss BD. Evaluation of web-based osteoporosis educational materials. $J$ Womens Health (Larchmt). 2005;14:936-945.

106. Walsh TM, Volsko TA. Readability assessment of internet-based consumer health information. Respir Care. 2008;53:1310-1315.

107. Ware J Jr, Kosinski M, Keller SD. A 12-item Short-Form Health Survey: construction of scales and preliminary tests of reliability and validity. Med Care. 1996;34:220-233.

108. Ware JE Jr, Sherbourne CD. The MOS 36-item short-form health survey (SF-36): I. Conceptual framework and item selection. Med Care. 1992;30:473-483.

109. Washburn RA, Smith KW, Jette AM, Janney CA. The Physical Activity Scale for the Elderly (PASE): development and evaluation. J Clin Epidemiol. 1993;46:153-162.

110. Weiss BD. Health Literacy and Patient Safety: Help Patients Understand: Manual for Clinicians. 2nd ed. Chicago, IL: AMA Foundation; 2007. Available at: http://med.fsu.edu/userFiles/ file/ahec_health_clinicians_manual.pdf. Accessed August 19, 2015.

111. Zahiri CA, Schmalzried TP, Szuszczewicz ES, Amstutz HC. Assessing activity in joint replacement patients. J Arthroplasty. 1998;13:890-895. 